\title{
Depression in children and adolescents
}

The EBMH Notebook summarises key messages about depression in children and adolescents, sourced from Clin Evid Concise 2003;1 0:62-4. For this review, Clinical Evidence Concise searched and appraised material published until September 2002.

\section{Definition}

Compared with adult depression, depression in children (6-12 years) and adolescents (13-18 years) may have a more insidious onset, may be characterised more by irritability than sadness, and occurs more often in association with other conditions such as anxiety, conduct disorder, hyperkinesis, and learning problems. ${ }^{1}$

\section{Incidence/prevalence}

Estimates of prevalence of depression among children and adolescents in the community range from $2-6 \%{ }^{2-3}$ Prevalence tends to increase with age, with a sharp rise around onset of puberty. Pre-adolescent boys and girls are affected equally by the condition, but depression is seen more frequently among adolescent girls than boys.

\section{Aetiology/risk factors}

The aetiology is uncertain, but may include genetic vulnerability, ${ }^{5}$ childhood events and current psychosocial adversity.

\section{Prognosis}

In children and adolescents, the recurrence rate following a first depressive episode in childhood or adolescence is $70 \%$ by 5 years, which is similar to the recurrence rate in adults. It is not clear if this is related to severity of depression. ${ }^{4}$ Young people experiencing a moderate to severe depressive episode may be more likely than adults to have a manic episode within the next few years. ${ }^{4-6}$ Trials of treatment for child and adolescent depression have found high rates of spontaneous remission (as much as two thirds of people in some inpatient studies).

\section{What are the effects of treatments?}

BENEFICIAL

Cognitive therapy (in mild to moderate depression)

One systematic review in children and adolescents with mild to moderate depression has found that cognitive behavioural therapy significantly improves symptoms compared with non-specific support.

\section{LIKELY TO BE BENEFICIAL}

Interpersonal therapy in adolescents (in mild to moderate depression)

Two RCTs found that interpersonal therapy versus clinical monitoring or waiting list control significantly increased recovery rate over 12 weeks in adolescents with mild to moderate depression.

\section{TRADE OFF BETWEEN BENEFITS AND HARMS}

Selective serotonin reuptake inhibitors

One RCT found no significant difference, one RCT found equivocal results (statistically significant differences on some depression measures but not others), and one RCT found a significant improvement in depressive symptoms with fluoxetine versus placebo after 8-9 weeks. One RCT found that, in adolescents with major depression, paroxetine versus placebo significantly improved remission after 8 weeks. We found no
RCTs on other selective serotonin reuptake inhibitors. Selective serotonin reuptake inhibitors are frequently associated with dizziness, lightheadedness, drowsiness, poor concentration, nausea, headache, and fatigue if treatment is reduced or stopped.

\section{UNKNOWN EFFECTIVENESS}

Cognitive therapy (depressed adolescents with depressed parent)

One RCT in depressed adolescents with depressed parents found no significant difference in recovery from depression with cognitive behavioural therapy plus usual care versus usual care alone over 2 years.

\section{Electroconvulsive therapy}

We found no RCTs on electroconvulsive therapy in children and adolescents with depression.

\section{Intravenous clomipramine (adolescents)}

One small RCT found that in non-suicidal adolescents, intravenous clomipramine versus placebo significantly reduced depression scores at 6 days. However, the trial was too small and brief for us to draw reliable conclusions.

\section{Lithium}

One RCT found no significant difference with lithium versus placebo in global assessment or depression scores after 6 weeks in children with depression and family history of bipolar affective disorder. Lithium was associated with adverse effects.

\section{Long term effects of treatments}

We found no systematic review or RCTs examining long term outcomes of interventions for depression in children and adolescents.

\section{Monoamine oxidase inhibitors}

One RCT found insufficient evidence to compare moclobemide versus placebo in children aged 9-15 years with major depression. We found no RCTs on non-reversible monoamine oxidase inhibitors in children or adolescents.

\section{St John's Wort}

We found no RCTs on St John's Wort (Hypericum perforatum) in children or adolescents with depression.

\section{Venlafaxine}

One RCT found no significant difference with venlafaxine versus placebo in improvement of depressive symptoms in children and adolescents with major depression after 6 weeks.

\section{Family therapy; group treatments other than cognitive behavioural therapy}

We found insufficient evidence in children and adolescents about the effects of these interventions.

\section{UNLIKELY TO BE BENEFICIAL}

Oral tricyclic antidepressants (adolescents)

One systematic review found no significant difference with oral tricyclic antidepressants (amitriptyline, desipramine, imipramine, nortriptyline) versus placebo in depression scores in adolescents and children with depression. Subgroup analyses 
found that oral tricyclic antidepressants versus placebo significantly reduced symptoms in adolescents but not in children. The review also found that oral tricyclic antidepressants were associated with adverse effects.

\section{LIKELY TO BE INEFFECTIVE OR HARMFUL}

Oral tricyclic antidepressants (children)

Subgroup analyses in one systematic review found no significant difference with oral tricyclic antidepressants (amitriptyline, desipramine, imipramine, nortriptyline) versus placebo in children with depression. The review also found that oral tricyclic antidepressants were associated with adverse effects.

University of Newcastle New South Wales, Australia

1 Birmaher B, Ryan ND, Williamson DE, et al. Childhood and adolescent depression: a review of the past 10 years, Part I. I Am Acad Child Adolesc Psychiatry 1996;35:1427-39.

2 Costello EJ, Angold A, Burns BI, et al The Great Smoky Mountains Study of Youth Goals, design, methods, and the prevalence of DSM-III-R disorders. Arch Gen Psychiatry 1996;53:1129-36.

3 Costello EJ. Developments in child psychiatric epidemiology. J Am Acad Child Adolesc Psychiatry 1989:28:836-41.

4 Lewinsohn PM, Rohde P, Seely JR. Major depressive disorder in older adolescents: prevalence, risk factors, and clinical implications. Clin Psychol Rev
5 Rice F, Harold G, Thapar A. The genetic aetiology of childhood depression: a review.J Child Psychol Psychiatry 2002;43:65-79.

6 Geller B, Fox LW, Fletcher M. Effect of tricyclic antidepressants on switch. JAm Acad Child Adolesc Psychiatry 1993;32:43-50.

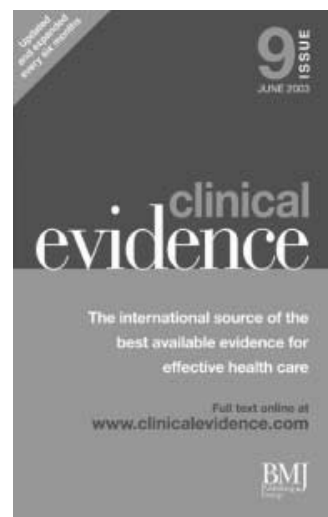

The full text of Clinical Evidence is updated monthly online a www.clinicalevidence.com. Information on subscriptions is available from CEsubscriptions@bmjgroup.com,ph + 44(0)20 73836270 (or, for North and South America, clinevid@pmds.com, ph 1-800-373-2897). Orders can also be made online. 